\title{
Technical Section
}

\author{
TECHNICAL NOTES \& TIPS
}

\section{Technical Notes}

\section{Laparascopic access: a different approach}

S ELSAYED, M NELSON, A FEROZ, KD VELLACOTT

Surgical Directorate, Royal Gwent Hospital, Newport, UK

\section{CORRESPONDENCE TO}

Dr S Elsayed, Surgical Directorate, Royal Gwent Hospital, Newport NP20 2UB, UK. T: +44 (0)1633 234160; M: +44

(0)7980 299325; E: sherief@doctor.com

\section{BACKGROUND}

A technique of access for laparoscopic cholecystectomy is described in which the first port, to be used for insufflation, is created in the epigastrium. Many of the complications associated with operative laparoscopy arise when creating the pneumoperitoneum (e.g. subcutaneous emphysema and gas embolism) or from injury to internal structures during abdominal entry. ${ }^{1,2}$ Traditionally, in open trocar placement, a peritoneal cut-down is made below the

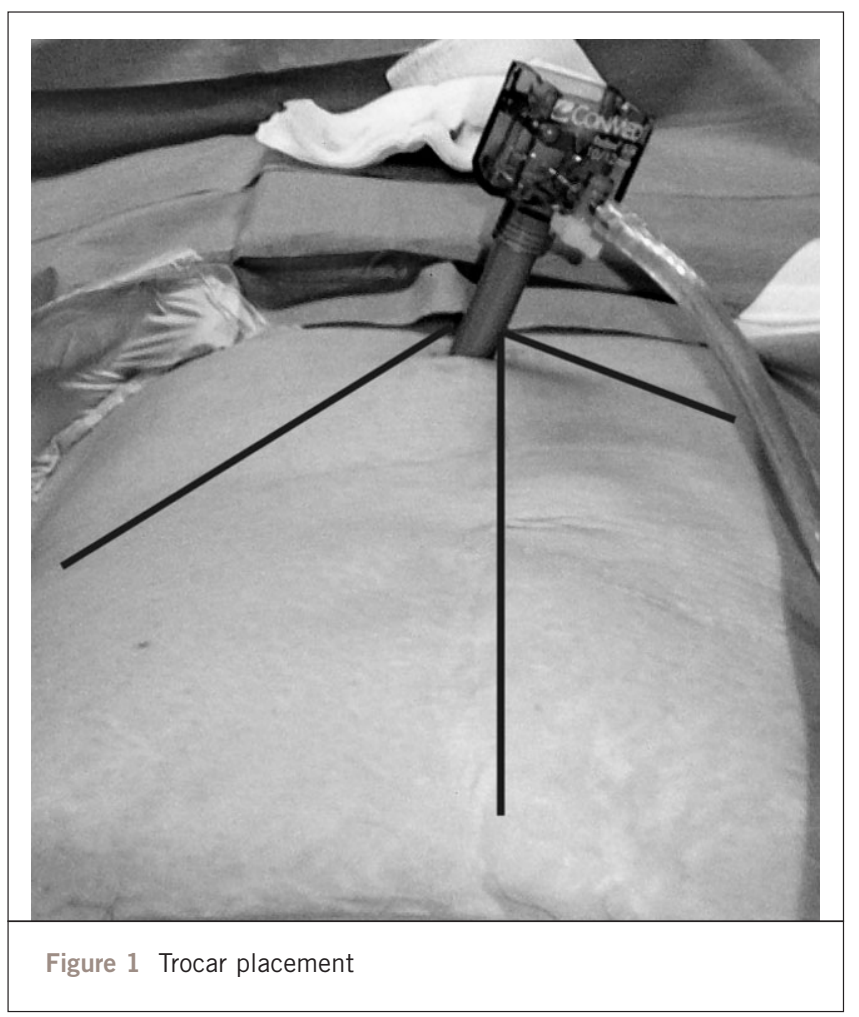

umbilicus. The trocar is then inserted under direct visualisation and the abdomen insufflated. Such injuries are especially likely to occur in patients who have had previous abdominal surgery, when adhesions may be problematic.

\section{TECHNIQUE}

A $1-\mathrm{cm}$ incision is made in the epigastric area, just to the right of the midline. A disposable trocar is inserted and the depth of insertion is checked with the laparoscope prior to insufflation. During insertion, the trocar is aimed towards the liver. The patient is kept slightly head-up and all have a nasogastric tube inserted to ensure that the stomach is deflated.

\section{DISCUSSION}

We have used this technique in over 500 cases over the past 4 years. One complication arose directly due to the method of insertion, namely damage to a moderate-sized vessel. This required conversion to open surgery. We believe that this technique lessens the risk of injury to bladder, bowel or major vessels. It is particularly useful for those patients with previous abdominal incisions, for whom this technique was initially used.

\section{References}

1. Yerdel MA, Karayalcin K, Koyuncu A, Akin B, Koksoy C, Turkcapar AG et al. Direct trocar insertion versus Veress needle insertion in laparoscopic cholecystectomy. Am J Surg 1999; 177: 247-9.

2. McKernan JB, Champion JK. Access techniques: Veress needle - initial blind trocar insertion versus open laparoscopy with the Hasson trocar. Endosc Surg Allied Technol 1995 ; 3: 35-8.

\section{Antegrade porridge enema to assess anorectal function after severe perineal sepsis}

RN SAUNDERS, WM THOMAS

Department of General Surgery, Leicester General Hospital, Leicester, UK

\section{CORRESPONDENCE TO}

Mr RN Saunders, SpR in General Surgery, Leicester General Hospital, Gwendolen Road, Leicester LE5 4PW, UK. T: +44 (0)116 2490490 ext 4608; E: rnsaunders19@hotmail.com

\section{BACKGROUND}

The management of severe perineal sepsis involves the drainage of abscesses, debridement of necrotic or devitalised tissue and, 